\title{
Analytical Procedures for Cadmium Determination in Facial Make-Up Samples by Graphite Furnace AAS
}

\author{
Ariane Isis Barros, Kelber Miranda, Edilene Cristina Ferreira, and José Anchieta Gomes Neto* \\ São Paulo State University, Analytical Chemistry Department \\ P.O. Box 355, 14801-970, Araraquara - SP, Brazil
}

\section{INTRODUCTION}

Human exposure to cadmium, an extremely toxic metal, can commonly occur through a variety of routes including atmospheric emission, food and drink ingestion, cigarette smoking, use of facial cosmetics, etc. (1). Health implications related to cadmium exposure are aggravated by the relative inability of human beings to excrete this metal. Even at low levels of exposure, cadmium may damage a functional unit of the kidney first manifested by leakage of essential ions, such as $\mathrm{Ca}^{2+}$, into the urine. Loss of calcium due to the toxic effects of cadmium on the kidney can lead to weakening of the bones (2).

In relation to facial cosmetics, cadmium impurities occur mainly in pigments of facial make-up products such as blushes, eye shadow, facial powders, etc. (3). Though the concentration of cadmium in facial make-up can be in trace amounts (4), the absorption of $0.3-0.8 \%$ of this metal through the skin (5) may cause deleterious effects to the human body (6). For this reason, cadmium was banned from being intentionally added to cosmetics in the European Union, Canada, and in the United States. Canada and Germany established the maximum concentration for cadmium as impurity in cosmetics at $3 \mathrm{mg} \mathrm{kg}^{-1}$ and $5 \mathrm{mg} \mathrm{kg}^{-1}$, respectively $(7,8)$.

Procedures for the determination of cadmium in facial make-up samples found in the literature usu-

Corresponding autbor.

E-mail: anchieta@iq.unesp.br

Tel: +551633019611

Fax: +551633222308

\section{ABSTRACT}

This paper describes the development of analytical procedures for the determination of cadmium in facial make-up based on line-source graphite furnace AAS (LS-GFAAS) and direct solid sampling (DSS) coupled to a high-resolution continuum source graphite furnace AAS (HRCS-GFAAS). Eye shadow, blush, and compact powder samples were analyzed by LS-GFAAS after microwave-assisted digestion with an $\mathrm{HNO}_{3} / \mathrm{H}_{2} \mathrm{O}_{2} / \mathrm{HF}$ mixture. Use of boric acid to eliminate $\mathrm{HF}$ from the digests was not feasible due to precipitation. Ammonium hydroxide was then dispensed into the graphite platform to eliminate HF and reduce digest acidity. The DSS HR-CS GFAAS procedure did not require any previous treatment. Both proposed procedures were validated using a certified reference material. Then, cadmium was determined in six facial make-up samples by LS-GFAAS and DSS HR-CS GFAAS with calibration against aqueous standard solutions. A paired $t$-test at a $95 \%$ confidence level showed that the DSS HR-CS GFAAS procedure enabled the achievement of similar results as those obtained by LS-GFAAS after acid digestion. The precision, expressed as the relative standard deviation, varied from 2.0 to $9.1 \%$ (LS-GFAAS) and from 1.0 to $11.1 \%$ (DSS HR-CS GFAAS). The DSS HR-CS GFAAS procedure was then applied for the determination of cadmium in 30 blush samples and 130 eye shadow samples of different brands and colors. The cadmium concentration varied from 12 to $111 \mu \mathrm{g} \mathrm{kg}^{-1}$ in the blush samples and from 5.1 to $198 \mu \mathrm{g} \mathrm{kg}^{-1}$ in the eye shadow samples. ally require wet digestion with strong acids at high temperatures, followed by determination using flame atomic absorption spectrometry (FAAS) $(9,10)$, graphite furnace atomic absorption spectrometry (GFAAS) (11), inductively coupled plasma optical emission spectrometry (ICP-OES) $(12,13)$, or inductively coupled plasma mass spectrometry (ICP-MS) $(13,14)$. GFAAS and ICPMS both provide adequate sensitivity for cadmium determination.

However, the latter is a much more expensive instrumentation when considering the purchasing and running costs. Therefore, GFAAS appears to be an excellent option. Direct solid sampling high-resolution continuum source graphite furnace atomic absorption spectrometry (DSS HR-CS GFAAS) with CCD array detection (15) is another alternative for the determination of trace metals in facial make-up $(16,17)$. It provides low detection limits, permits calibration with aqueous standards, offers improved background correction, and minimizes sample preparation (18-21).

This paper reports the development of reliable analytical procedures for the determination of cadmium in facial make-up based on line-source GFAAS and DSS HRCS GFAAS.

\section{EXPERIMENTAL}

\section{Instrumentation}

A PerkinElmer SIMAA ${ }^{\mathrm{TM}} 6000$ simultaneous multi-element atomic absorption spectrometer, equipped with a transversely heated graphite atomizer (THGA ${ }^{\mathrm{TM}}$ ), longitudinal Zeeman-effect background (BG) correction, and an AS-72 autosampler (PerkinElmer, Inc., Shelton, 


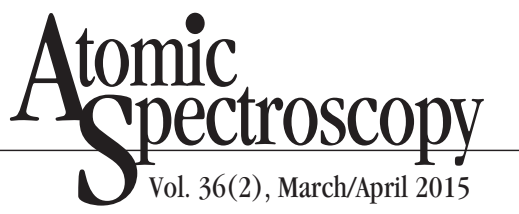

CT, USA) was used. PerkinElmer hollow cathode lamps (HCL) were used for the determination of $\mathrm{Cd}$ at the analytical wavelength of 228.8 $\mathrm{nm}$, and the lamp current was 10 $\mathrm{mA}$. The atomic signals were measured in triplicate and based on peak area mode. High-purity argon (99.999\%, White Martins, Brazil) was used as the protective and purge gas at the $250 \mathrm{~mL} \mathrm{~min}^{-1}$ flow rate. It should be pointed out that the experiments were carried out using the stabilized temperature platform furnace, so-called STPF conditions, for Zeeman-effect background correction (22). The heating program of the atomizer used for the determination of cadmium is shown in Table I.

For the determination of Cd by direct solid sampling, an Analytik Jena ContrAA 700 high-resolution atomic absorption spectrometer was used (Analytik Jena, Germany). This spectrometer is equipped with a Xenon short-arc lamp (XBO 301, $300 \mathrm{~W}$, GLE, Berlin, Germany) as a continuum radiation source, a compact high-resolution monochromator comprising a prism, and an Echelle grating with a spectral bandwidth lower than 2 pm per pixel in the far ultraviolet range, and a charge-coupled device (CCD) array detector. The ContrAA 700 is equipped with a Sartorius WZ2PW micro-balance (Göttingen, Germany) with a precision of $0.001 \mathrm{mg}$ that allows samples to be weighed directly onto the graphite platform. Pyrolytic graphite-coated solid sampling tubes without a dosing hole were used. High-purity argon was used as the purge and protective gas.

An Anton Paar Multiwave ${ }^{\circledR}$ microwave oven (Graz, Austria), equipped with a 6-position rotor and 50-mL PFA vessels (minimum filling volume of $6 \mathrm{~mL}$ ), was used to digest the samples for subsequent determination of cadmium by LSGFAAS.

TABLE I

Heating Program for Cadmium Determination in Facial Make-Up Samples by LS-GFAAS

\begin{tabular}{lcccc}
\hline Step & $\begin{array}{c}\text { Temp. } \\
\left({ }^{\circ} \mathrm{C}\right)\end{array}$ & $\begin{array}{r}\text { Ramp Time } \\
(\mathrm{s})\end{array}$ & $\begin{array}{c}\text { Hold Time } \\
(\mathrm{s})\end{array}$ & $\begin{array}{c}\text { Argon Flow Rate } \\
\left(\mathrm{mL} \mathrm{min}^{-1}\right)\end{array}$ \\
\hline Drying 1 & 110 & 10 & 30 & 250 \\
Drying 2 & 130 & 10 & 30 & 250 \\
Drying 3 & 200 & 10 & 30 & 250 \\
Pyrolysis & 500 & 5 & 60 & 250 \\
Atomization & 1600 & 0 & 5 & 0 \\
Cleaning & 2500 & 1 & 5 & 250 \\
\hline
\end{tabular}

\section{Reagents, Analytical Solutions,} and Samples

Deionized water $(18 \Omega \mathrm{M} \mathrm{cm}$ resistivity) obtained with a Millipore Rios $5{ }^{\circledR}$ reverse osmosis and a Millipore Milli-Q ${ }^{\circledR}$ Academic deionizer system (Millipore, Bedford, MA, USA) was used to prepare all solutions. All glassware and polypropylene flasks were washed with Extran ${ }^{\circledR}$ laboratory detergent and soaked in $10 \%$ (v/v) $\mathrm{HNO}_{3}$ for 24 hours, then rinsed with deionized water prior to use. Nitric acid (69\%, J.T. Baker, Deventer, Holland), $\mathrm{H}_{2} \mathrm{O}_{2}$ (30\%, Merck, Darmstadt, Germany) and hydrofluoric acid (48\%, Merck) were used for sample digestion. Ammonium hydroxide (40\%, Synth ${ }^{\circledR}$, São Paulo, Brazil) was dispensed into the graphite platform in order to neutralize the hydrofluoric acid during determinations by LSGFAAS.

Chemical modifier solutions containing $1000 \mathrm{mgL}^{-1} \mathrm{Pd}\left(\mathrm{NO}_{3}\right)_{2}$ and $500 \mathrm{mg} \mathrm{L}^{-1} \mathrm{Mg}\left(\mathrm{NO}_{3}\right)_{2}$ were prepared by appropriate dilution of $10 \mathrm{~g} \mathrm{~L}^{-1} \mathrm{Pd}\left(\mathrm{NO}_{3) 2}\right.$ and dissolution of $\mathrm{Mg}\left(\mathrm{NO}_{3}\right)_{2} \cdot 6 \mathrm{H}_{2} \mathrm{O}$ (Suprapur ${ }^{\circledR}$, Merck, Darmstadt, Germany). These solutions were prepared in $0.05 \%(\mathrm{~m} / \mathrm{v})$ Triton ${ }^{\circledR} \mathrm{X}-100$ (Mallinckrodt Baker, Paris, KY, USA).

Aqueous calibrations comprising the 5-50 pg (DSS HR-CS GFAAS) and $0.2-4.0 \mu \mathrm{g} \mathrm{L}^{-1}$ (LS GFAAS) inter- vals were obtained by proper dilution of the $1000 \mathrm{mg} \mathrm{L}^{-1} \mathrm{Cd}$ stock solution (Titrisol ${ }^{\circledR}$, Merck). The autosampler wash solution was $0.14 \mathrm{~mol} \mathrm{~L}^{-1} \mathrm{HNO}_{3}+0.1 \%$ (v/v) Triton ${ }^{\circledR} \mathrm{X}-100$. All solutions were stored in high-density polypropylene bottles (Nalgene ${ }^{\circledR}$, Rochester, NY, USA).

The 2709a San Joaquim Soil certified reference material from the National Institute of Standards and Technology (Gaithersburg, MD, USA) was used for validation.

Facial make-up samples including eye shadows, blushes, and compact facial powders of different brands and colors were purchased in São Paulo State, Brazil.

\section{Sample Preparation}

Eye shadow, blush, and compact powder samples were analyzed by DSS HR-CS GFAAS without any previous treatment. Amounts of around $0.2-0.4 \mathrm{mg}$ were directly transferred from their containers to the graphite platform.

The samples were analyzed by LS-GFAAS after microwave-assisted acid digestion. An amount of ca. $200 \mathrm{mg}$ was accurately weighed and transferred to microwave PFA vessels, followed by addition of $3.0 \mathrm{~mL}$ of concentrated nitric acid, $2.0 \mathrm{~mL}$ of hydrofluoric acid, and $1.0 \mathrm{~mL}$ of hydrogen peroxide. The 
mixture was submitted to the following heating: (a) 0-900 W, 15minute ramp; (b) $900 \mathrm{~W}, 30$-minute hold; (c) $0 \mathrm{~W}, 5$-minute ventilation. The maximum temperature reached was $200{ }^{\circ} \mathrm{C}$. The final digests were transferred to polypropylene flasks and diluted up to $30 \mathrm{~mL}$ with water. The addition of boric acid to the digests to neutralize HF was not feasible due to the formation of a precipitate. This fact may be explained due to the presence of high content of potassium sorbate in the facial make-up samples that may contribute to the formation of $\mathrm{KBF}_{4}$ which has a relatively low solubility (23). Instead of using boric acid, ammonium hydroxide was initially dispensed into the graphite platform in order to neutralize $\mathrm{HF}$ in the digests.

\section{RESULTS AND DISCUSSION}

\section{Analytical Procedure Using LS-GFAAS}

The effect of pyrolysis and atomization temperatures on cadmium sensitivity in aqueous medium and eye shadow digest is presented in Figure 1. The optimum pyrolysis and atomization temperatures were $500 \mathrm{C}^{\circ}$ and $1600 \mathrm{C}^{\circ}$, respectively.
The optimized heating program is described in Table I. During optimization of the heating program, $\mathrm{NH}_{4} \mathrm{OH}$ was directly introduced into the graphite furnace to neutralize the strongly acidic digests and to prevent the graphite tube from wearing out faster. First, $15 \mu \mathrm{L}$ of $\mathrm{NH}_{4} \mathrm{OH}$, followed by $20 \mu \mathrm{L}$ of aqueous standard/sample digest, was dispensed into the graphite tube, and the "drying 1 " step was performed. Then, $5 \mu \mathrm{L}$ of the matrix modifier containing $5.0 \mu \mathrm{g}$ $\mathrm{Pd}\left(\mathrm{NO}_{3}\right)_{2}$ plus $2.5 \mu \mathrm{gg}\left(\mathrm{NO}_{3}\right)_{2}$ was added, and the rest of the heating program was executed. The sequence of injections and the drying temperatures were established with the purpose of neutralizing the digests and eliminating the species formed with $\mathrm{NH}_{4} \mathrm{OH}$. When the sample digest is mixed with $\mathrm{NH}_{4} \mathrm{OH}$, the following reactions may occur (23):

(a)

$$
\mathrm{NH}_{4} \mathrm{OH}+\mathrm{HF} \leftrightarrows \mathrm{NH}_{4} \mathrm{~F}+\mathrm{H}_{2} \mathrm{O}
$$

(b)

$\mathrm{NH}_{4} \mathrm{OH}+\mathrm{HNO}_{3} \leftrightarrows \mathrm{NH}_{4} \mathrm{NO}_{3}+\mathrm{H}_{2} \mathrm{O}$

(c)

$$
\mathrm{NH}_{4} \mathrm{OH}(\mathrm{aq}) \rightarrow \mathrm{NH}_{3(\mathrm{~g})}+\mathrm{H}_{2} \mathrm{O}
$$

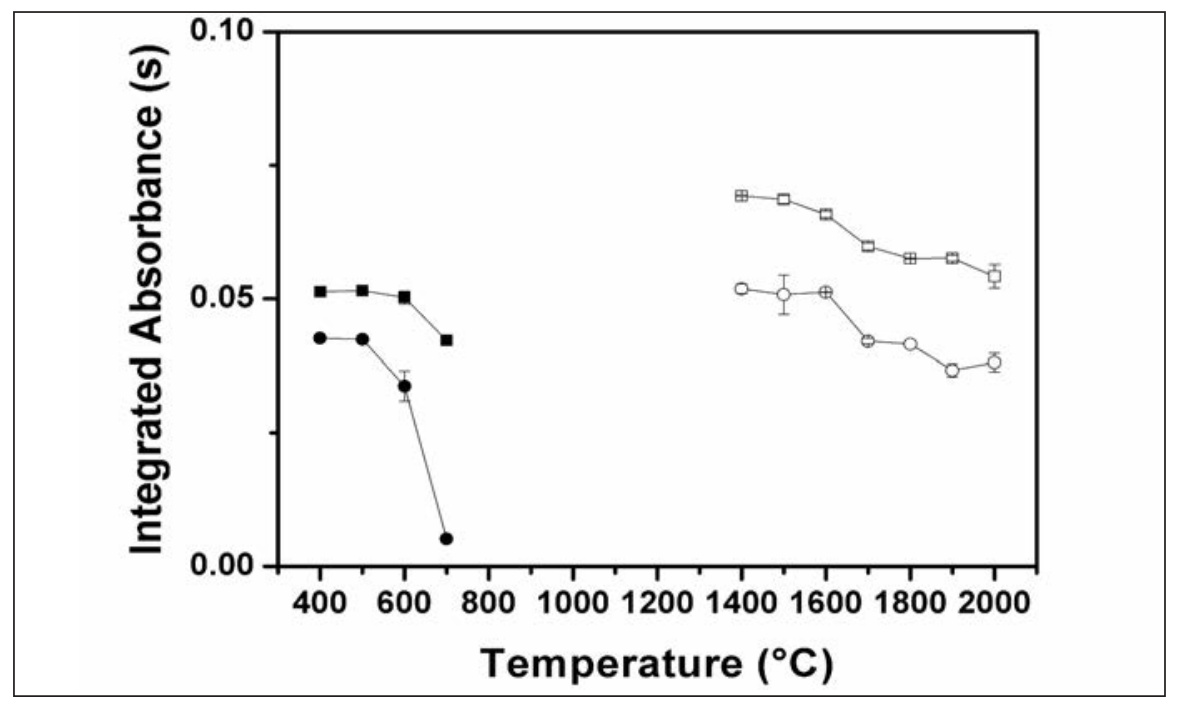

Fig. 1. Pyrolysis (black symbol) and atomization (empty symbol) temperature curves for Cd by LS-GFAAS. Data refer to aqueous ( $\square$ ) and eye shadow digest (○) containging $1.0 \mathrm{mg} \mathrm{L}^{-1} \mathrm{Cd}$ and $0.9 \mathrm{mg} \mathrm{L}^{-1} \mathrm{Cd}$, respectively.

During the "drying 1 " step at $110^{\circ} \mathrm{C}$, the remaining $\mathrm{HF}$ was eliminated and $\mathrm{NH}_{4} \mathrm{~F}$ was decomposed into $\mathrm{NH}_{3}$ and $\mathrm{HF}$. Then, the matrix modifier was added and $\mathrm{NH}_{4} \mathrm{NO}_{3}$ was decomposed and eliminated during the "drying 2 " and "drying 3 " steps. The matrix modifier was added after elimination of $\mathrm{NH}_{4} \mathrm{OH}$ in order to avoid the formation of $\left[\mathrm{Pd}\left(\mathrm{NH}_{3}\right)_{4}\right]^{2+}(23)$ which could interfere with the action of palladium as a chemical modifier.

\section{DSS HR-CS GFAAS Procedure}

The pyrolysis and atomization temperatures for cadmium were first evaluated using an aqueous standard solution and $\mathrm{Pd}+\mathrm{Mg}$ modifier. Then, pyrolysis and atomization curves were established for three solid facial make-up samples using the same modifier. The results obtained with aqueous solution and solid samples are shown in Figures $2 \mathrm{a}$ and $2 \mathrm{~b}$, respectively. A pyrolysis temperature of $600^{\circ} \mathrm{C}$ was adequate to eliminate the complex matrix (14) of the facial makeup samples. An atomization temperature of $1700^{\circ} \mathrm{C}$ was chosen because it provided a single sharp peak for the atomic absorption signal, a fast return of the signal to the baseline, and better precision. The temperature program used for the determination of cadmium in facial make-up samples by DSS HR-CS GFAAS is presented in Table II.

Studies on minimum mass and homogeneity were then conducted by analyzing different masses (0.05-1.0 mg) of three facial makeup samples (eye shadow sample, blush sample, and compact powder sample). The most accurate and precise results were obtained for sample amounts in the $0.2-0.4 \mathrm{mg}$ range. Therefore, $0.3 \mathrm{mg}$ of sample mass was used in all further investigations. 


\section{Atomic Spectroscopy \\ Vol. 36(2), March/April 2015}
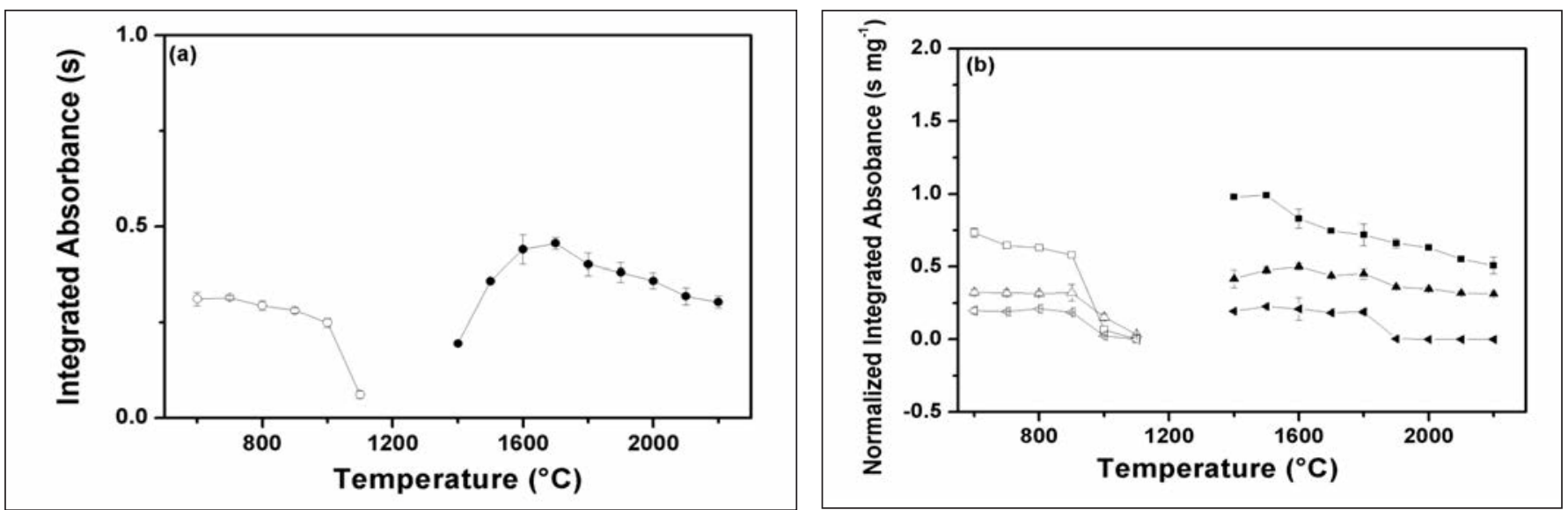

Fig. 2. Pyrolysis (empty symbol) and atomization (black symbol) temperature curves for Cd by DSS HR-CS GFAAS employing (a) aqueous medium and (b) sample media. Data refer to $50 \mathrm{pg} C d$ (a), $100 \mathrm{pg} C d$ in eye shadow (b, $\mathrm{O}$ ), $51 \mathrm{pg} C d \mathrm{in}$ blush (b, $\triangle \mathbf{\Delta}$ ), and $33 \mathrm{pg}$ Cd in compact powder $(\triangleleft<)$.

TABLE II

Temperature Program for Cadmium Determination in Facial Make-Up Samples by DSS HR-CS GFAAS

\begin{tabular}{lcccc}
\hline Step & $\begin{array}{c}\text { Temp. } \\
\left({ }^{\circ} \mathrm{C}\right)\end{array}$ & $\begin{array}{c}\text { Ramp } \\
\left({ }^{\circ} \mathrm{C} / \mathrm{s}\right)\end{array}$ & $\begin{array}{c}\text { Hold } \\
\text { Time }\end{array}$ & $\begin{array}{c}\text { Argon } \\
\text { Flow Rate } \\
\left(\mathrm{L} \mathrm{min}{ }^{-1}\right)\end{array}$ \\
\hline Drying 1 & 110 & 10 & 10 & 2.0 \\
Drying 2 & 130 & 5 & 10 & 2.0 \\
Pyrolysis & 600 & 50 & 30 & 2.0 \\
Auto-zero & 600 & 0 & 5 & 0 \\
Atomization & 1700 & 3000 & 4 & 0 \\
Cleaning & 2500 & 500 & 5 & 2.0 \\
\hline
\end{tabular}

${ }^{a}$ Step to record a series of baseline spectra immediately

before atomization.

\section{Figures of Merit}

The figures of merit for the determination of cadmium in facial make-up samples using both analytical procedures (LS-GFAAS and DSS HR-CS GFAAS) were determined. The limit of detection (LOD) and the limit of quantification (LOQ) were calculated as the concentration corresponding to 3 - and 10 -fold the standard deviation of 10 independent sample blanks, divided by the slope of the analytical curve (24). For DSS HR-CS GFAAS, the standard deviation of the blank was calculated by repeatedly inserting an empty solid sampling platform (only containing the modifier) and running the temperature program (25). The limit of detection (LOD) and quantification (LOQ), the characteristic mass $\left(\mathrm{m}_{0}\right)$, the linear calibration range, and the correlation coefficient (R) are presented in Table III.

\section{Validation and Application of Analytical Procedures}

The results obtained for $\mathrm{Cd}$ in a certified reference material (CRM) NIST 2709a San Joaquim Soil (National Institute for Standards
TABLE III by LS-GFAAS and DSS HR-CS GFAAS

\begin{tabular}{lrc}
\hline Parameter & LS GFAAS & DSS HR-CS GFAAS \\
\hline LOD $\left(\mu \mathrm{g} \mathrm{kg}^{-1}\right)$ & 4.5 & 0.0020 \\
LOQ $\left(\mu \mathrm{g} \mathrm{kg}^{-1}\right)$ & 15 & 0.0067 \\
$\mathrm{~m}_{0}(\mathrm{pg})$ & - & 0.56 \\
Linear working range & $0.2-4.0^{\mathrm{a}}$ & $5.0-50^{\mathrm{b}}$ \\
$\mathrm{R}$ & 0.9942 & 0.9964 \\
\hline
\end{tabular}

${ }^{\mathrm{a}} \mu \mathrm{g} \mathrm{L} \mathrm{L}^{-1} ;{ }^{\mathrm{b}} \mathrm{pg}$ and Technology, Gaithersburg, MD, USA) and six facial make-up samples by LS-GFAAS and DSS HR-CS GFAAS are listed in Table IV. According to the results for the CRM, both proposed procedures with calibration against aqueous standard solutions provided accurate results. A paired $t$-test at the 95\% confidence level showed that the DSS HR-CS GFAAS procedure enabled the achievement of similar results as those obtained by LSGFAAS after acid digestion. The precision, expressed as the relative standard deviation (RSD), varied 
TABLE IV

Results (mean $\pm \mathrm{SD}, \mu \mathrm{g} \mathrm{kg}^{-1}$ ) for Cadmium Determination $(\mathrm{n}=3$ ) in CRM and Samples by LS-GFAAS and DSS HR-CS GFAAS

\begin{tabular}{lccc}
\hline Sample & $\begin{array}{c}\text { Certified } \\
\text { Value } \\
\left(\mu \mathrm{g} \mathrm{kg}^{-1}\right)\end{array}$ & $\begin{array}{c}\text { LS-GFAAS } \\
\left(\mu \mathrm{g} \mathrm{k}^{-1}\right)\end{array}$ & $\begin{array}{c}\text { DSS JRC } \\
\text { GFAAS } \\
\left(\mu \mathrm{kg}^{-1}\right)\end{array}$ \\
\hline San Joaquim Soil (NIST 2709a) & $371 \pm 2$ & $370 \pm 11$ & $373 \pm 18$ \\
Eye shadow (rose) & - & $100 \pm 2$ & $98 \pm 5$ \\
Eye shadow (blue) & - & $86 \pm 4$ & $87 \pm 2$ \\
Blush (orange) & - & $51 \pm 1$ & $51.7 \pm 0.5$ \\
Blush (rose) & - & $38 \pm 2$ & $40 \pm 2$ \\
Compact facial powder (light brown) & - & $33 \pm 3$ & $30.3 \pm 0.6$ \\
Compact facial powder (dark brown) & - & $31 \pm 2$ & $27 \pm 3$ \\
\hline
\end{tabular}

TABLE $V$

Results (mean \pm SD, $\mu \mathrm{g} \mathrm{kg}^{-1}$ ) for Cadmium Determination $(\mathrm{n}=3)$ in Blush Samples by DSS HR-CS GFAAS

\begin{tabular}{lccccc}
\hline Sample $^{\mathrm{a}}$ & Light Pink & Dark Pink & Red & Coral & Brown \\
\hline BlushAdult A & $29.1 \pm 0.9$ & - & $111 \pm 7$ & - & - \\
BlushAdult B & $15.5 \pm 0.7$ & - & - & $17 \pm 1$ & - \\
BlushAdult C & - & - & - & $27 \pm 1$ & - \\
BlushAdult D & $12 \pm 1$ & - & - & $41 \pm 1$ & $13.6 \pm 0.2$ \\
BlushAdult E & $23 \pm 2$ & $32.027 \pm 0.009$ & $24 \pm 1$ & - & - \\
Blush Infant F & $38 \pm 2$ & - & - & - & - \\
\hline
\end{tabular}

${ }^{a}$ Make-up kit containing samples of different colors. The letters (A-F) indicate different brands.

TABLE VI

Results (mean \pm SD, $\mu$ g kg-1) for Cadmium Determination $(n=3)$ in Eye Shadow Samples by DSS HR-CS GFAAS

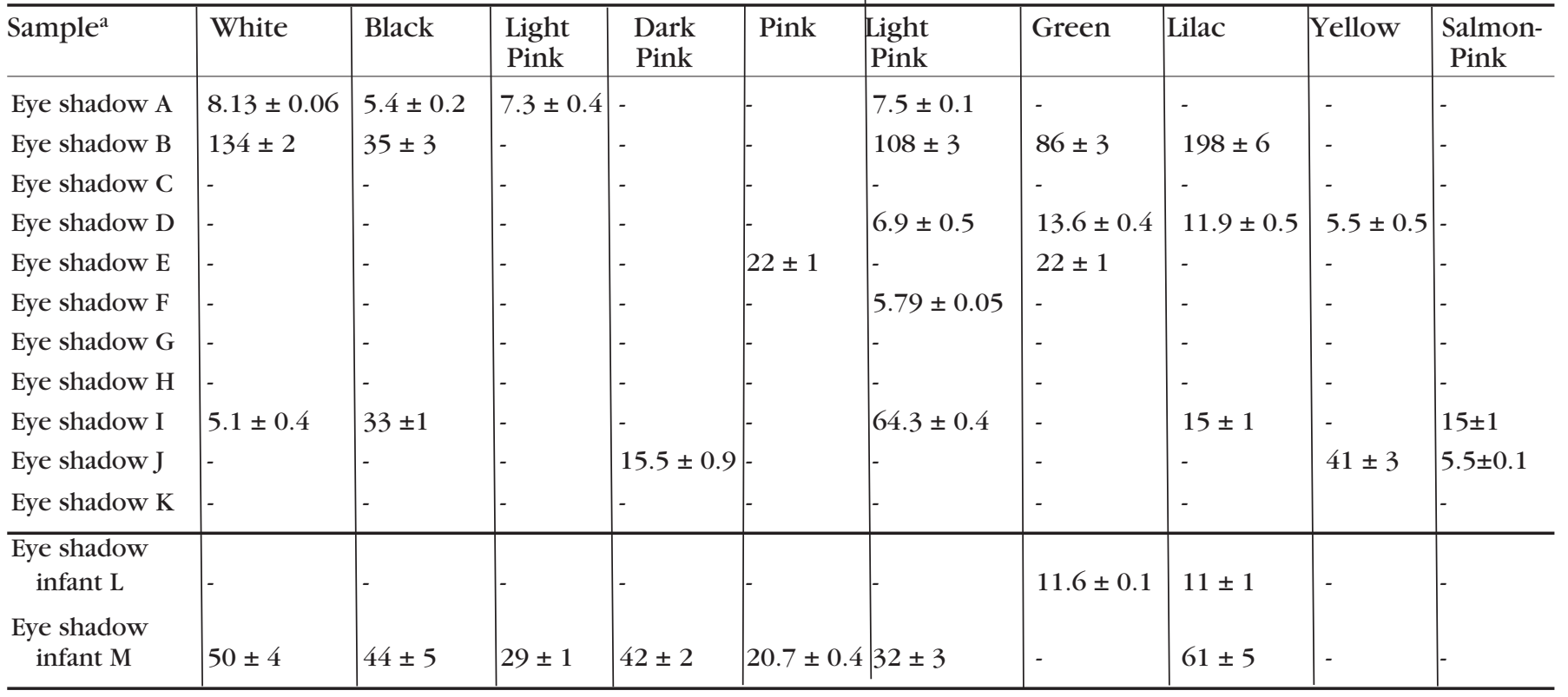

\footnotetext{
${ }^{a}$ Make-up kit containing samples of different colors. The letters A-M indicate different brands.
}

from 2.0 to $9.1 \%$ for the determinations by LS-GFAAS and from 1.0 to $11.1 \%$ when using DSS HR-CS GFAAS.

Considering the facilities of direct analysis, the DSS HR-CS GFAAS procedure was then applied to the determination of cadmium in 30 blush samples and 130 eye shadow samples of different brands, and the results are listed in Tables V and VI, respectively. Cadmium was detected in $40 \%$ of the blush samples and in $25 \%$ of the eye shadow samples. The concentration of cadmium varied from 12 to $111 \mu \mathrm{g} \mathrm{kg}^{-1}$ in the blush samples and from 5.1 to $198 \mu \mathrm{g} \mathrm{kg}^{-1}$ in the eye shadow samples, which shows that these values did not exceed the maximum concentration for cadmium as impurity in cosmetics as established in Canada (3 $\mathrm{mg} \mathrm{kg}^{-1}$ ).

\section{CONCLUSION}

This study evaluated two alternative procedures for the quantitative 
determination of cadmium in facial make-up samples. The first one employs $\mathrm{HNO}_{3} / \mathrm{H}_{2} \mathrm{O}_{2} / \mathrm{HF}$ microwave digestion, followed by LS-GFAAS detection. Instead of boric acid, $\mathrm{NH}_{4} \mathrm{OH}$ was directly introduced in the graphite furnace to eliminate HF in situ and to neutralize the strongly acidic digests. The second procedure based on DSS HR-CS GFAAS presented the following advantages in relation to the first one: (a) no sample preparation is required since the samples are directly transferred from their packages to the graphite furnace; (b) calibration with aqueous standards further simplifies the analytical procedure; (c) it provides lower detection limits; (d) higher sample throughput is obtained; and (e) it offers low comsumption of reagents and minimum generation of laboratory residues.

\section{ACKNOWLEDGMENT}

The authors thank the São Paulo Research Foundation (FAPESP) for financially supporting this work (Grant \#14/12595-1) and Post-Doctoral Fellowships to K.M. The authors also thank the Conselho Nacional de Desenvolvimento Científico e Tecnológico for fellowship to A.I.B. and researchship to J.A.G.N.

Received October 27, 2014

\section{REFERENCES}

1. H. Harmens et al., Environ. Pollut.158, 3144 (2010).

2. S. Satarug, M.R. Haswell-Elkins and M.R. Moore, Br. J. Nutr. 84, 791 (2000).

3. J. Godt, F. Scheidig, C. GrosseSiestrup, V. Esche, P. Brandenburg, A. Reich and D.A. Gronenberg, J. Occup. Med. Toxicol. 1, 1 (2006).

4. I. Lavilla, N. Cabaleiro, M. Costas, I. de la Calle and C. Bendicho, Talanta 80, 109 (2009).

5. ATSDR, Toxicological Profile for Cadmium, USA; Department of Health \& Human Services; Centers for Disease Control and Prevention; Agency for Toxic Substances and Disease Registry, Published Report (1993).

6. R.C. Wester, H.I. Maibach, L. Sedik, J. Melendres, S. DiZio and M. Wade, Fundam. Appl. Toxicol. 19, 1 (1992).

7. Bundesinstitut für Risikobewertung (BfR). Kosmetische Mittel: BfR empfiehlt Schwermetallgehalte über Reinheitsanforderungen der Ausgangsstoffe zu regeln, Stellungnahme Nr. 025/2006 des BfR vom 05. April 2006. Available at: http://www.bfr.bund.de/cm/343/ kosmetische_mittel_bfr_empfiehlt _schwermetallgehalte_ueber.pdf [Accessed 20 October 2014].

8. HC-SC, Health Canada-Santé Canada, 2012. Guidance on Heavy Metal Impurities in cosmetics. Available at: <http://www.hcsc.gc.ca/cps-spc/pubs/indust/ heavy_metals-metaux_lourds/ index-eng.php> [Accessed 20 October 2014].

9. I.C. Nnorom, J.C. Igwe and C.G. Oji-Nnorom, Afr. J. Biotechnol. 4, 1133 (2005).

10. J.A. Omolaoye, A. Uzairu and C.E. Gimba, Arch. Appl. Sci. Res. 2, 76 (2010).

11. A.A. Adepoju-Bello, O.O. Oguntibeju, R.A. Adebisi, N. Okpala and H.A.B. Coker, Afr. J. Biotechnol 11, 16360 (2012).

12. S. Liu, K.Hammond and A. RojasCheatham, Environ. Health Persp. 121, 705 (2013).

\section{Atomic Spectroscopy Vol. 36(2), March/April 2015}

13. ED, Environmental Defence Canada, 2011. Heavy metal hazard. The health risks of hidden heavy metals in face makeup. Environmental Defence (ED), Toronto, Canada. Available at:http://environmentaldefence.ca/ sites/default/files/report_files/Heav yMetalHazard\%20FINAL.pdf [Accessed 20 October 2014].

14. M.G. Volpe, M. Nazzaro, R. Coppola, F. Rapuano and R. P. Aquino, Microchem. J. 101, 65 (2012).

15. B. Welz, H. Becker-Ross, S. Florek and U. Heitmann, High-Resolution Continuum Source Atomic Absorption Spectrometry, Wiley-VCH, Weinheim, New York (2005).

16. S. Gunduz and S. Akman, Regul. Toxicol. Pharmacol. 65, 34 (2012).

17. R.Lemaire, D. Del Bianco,L.Garnier and J. L.Beltramo,Anal.Lett. 46, 2265 (2013).

18. I.N.B. Castilho, E.R. Pereira, B. Welz, A.A. Shaltout, E. Carasek and I.B. Gonzaga Martens, Anal. Methods 6, 2870 (2014).

19. D.M. Silvestre and C.S. Nomura, J. Agric. Food Chem. 61, 6299B (2013).

20. A.T. Duarte, M.B. Dessuy, M.G.R Vale, B. Welz and J.B. Andrade, Talanta 115, 55 (2013).

21. A.T. Duarte, M.B. Dessuy, M.M.Silva, M.G.R.Vale and B. Welz, Microchem. J. 96, 102 (2010).

22. W. Slavin, D.C. Manning, and G.R. Carnrick GR, At. Spectrosc. 2, 137 (1981).

23. A.I. Vogel and G. Svehia, Vogel's qualitative inorganic analysis, 7 th ed., Longman, UK (1996).

24. A.G. González and M.A. Herrador, Trends Anal. Chem. 26, 227 (2007).

25. U. Kurfürst, Solid Sample Analysis, Springer Verlag, Berlin, Germany (1998). 